\title{
Effects of LCF Loadings on the HCF Life of Notched Specimens in Ferritic-Bainitic Steel ${ }^{\star}$
}

\author{
Hadrien Bidouard, Thierry \\ Palin-Luc, Nicolas Saintier, \\ Talence, France, Christian \\ Dumas, Guyancourt, France, \\ Chalid El Dsoki, Heinz Kauf- \\ mann, and Cetin Morris Sonsino, \\ Darmstadt, Germany
}

Fatigue tests were performed on ferritic bainitic steel notched specimens $(\mathrm{Kt}=2.5)$ under load controlled constant amplitude loading. These tests show that under constant amplitude tension compression loading, periodical overloads application have a detrimental effect on the fatigue crack initiation strength for fully reversed load ratio $\left(R_{\sigma}=-1\right)$, while they have no influence under pulsating loading $\left(R_{\sigma}=0\right)$. A finite element analysis shows that in the fully reversed tension $\left(R_{\sigma}=-1\right)$, the stabilized cyclic behaviour at the notch root is an elastic-plastic shakedown while elastic shakedown is obtained under pulsated regime $\left(R_{\sigma}=0\right)$, so that we can consider that the local cyclic behaviour has an influence on the overload effect. However, the overload application does not imply a remarkable modification of the stress and strain field under the subsequent constant amplitude loading and can not explain such a fatigue strength decrease in fully reversed tension.

\section{Introduction}

Automotive safety components are designed against the initiation of a technically detectable fatigue crack $(\mathrm{a} \approx 1 \mathrm{~mm})$ occurring in areas with stress concentrations (notch, hole, rivet) in the finite fatigue (FF) and high-cycle fatigue (HCF) regimes under so-called service conditions with variable amplitudes. In notched areas, high stress/strain levels due to extreme use may occur during the car life with a small number of cycles and lead to macroscopic plastic strains. Such loadings can be assigned to the low cycle fatigue (LCF) regime (Figure 1).

Fatigue crack initiation (FCI) life assessments methods ${ }^{1}$ dedicated to fatigue life from LCF/FF to HCF exist in the literature [1-3]. However, although these methods can easily be applied to smooth

\footnotetext{
* Extended Version of the Contribution to the International Conference on Low Cycle Fatigue (LCF 6).

1 For estimating the life up to a technically detectable crack (which length $\sim 1 \mathrm{~mm}$ ) without any long crack propagation consideration.
}

specimens, the case of notched specimens is more complex. Computing the stress strain history at the notch root is a real difficulty. Moreover, only few experimental data concerning overload interaction are available [4-7]. The aim of this study is to investigate precisely the effect of loading corresponding to the LCF regime on the HCF behaviour of notched specimens. This consists in a first step towards the proposal of a methodology adapted for fatigue life assessment under variable amplitude loading with overloads.

\section{Fatigue Tests}

Experimental conditions. The material of this work is a ferritic-bainitic steel. The normalized quasi-static tension properties of this steel are: $\mathrm{E}=210 \mathrm{GPa}$, $\mathrm{R}_{\mathrm{p} 0.2} / \sigma_{\mathrm{D}}=1.79, \mathrm{R}_{\mathrm{m}} / \sigma_{\mathrm{D}}=2.2$ where $\sigma_{\mathrm{D}}$ is the fully reversed tension fatigue strength at $5 \cdot 10^{6}$ cycles on smooth specimens. In this study a large database of experimental HCF results has been generated with flat notched specimens with $\mathrm{Kt}=2.5$ (Figure 2). Such a stress

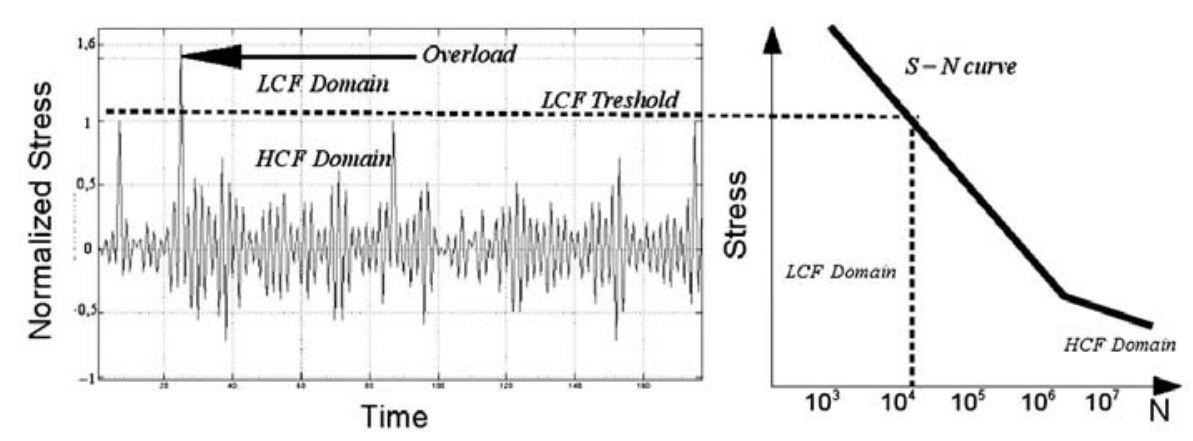

Figure 1. Cut-off of load time history with LCF/HCF interaction 
concentration was chosen because this is representative of industrial applications.

These tests were carried out with an Instron 8500 servo-hydraulic fatigue testing machine under load control, in air and room temperature at a frequency of $20 \mathrm{~Hz}$. Fatigue tests were stopped when a macroscopic fatigue crack of $\approx 1 \mathrm{~mm}$ (technical crack) was initiated at the notch. Crack detection was ensured in real time with a home made clip gauge extensometer, which monitored the hole diameter evolution versus time, and a specific home made electronic device stopping the test when the diameter evolution exceeds a threshold calibrated for detecting such a technical crack. This system separates an overload from the subsequent constant amplitude loading and does not stop the test on the overload.

Two types of test were carried out: constant amplitude loading (1) with and (2) without some periodical overloads as illustrated in Figure 3. Furthermore, two types of overloads were investigated: tension overloads and compression overloads with two occurrences (1/1000 and 1/10000 cycles). Their effects on the S-N curves of the notched specimens are investigated under fully reversed axial loading $\left(R_{\sigma}=-1\right)$, and under repeated pulsating axial loading $\left(R_{\sigma}=0\right)$.

Fatigue test results. Fatigue test results carried out under fully reversed loading $\left(\mathrm{R}_{\sigma}=-1\right)$ show an important fatigue strength decrease when periodical overloads are applied: the higher the overload occurrence, the smaller the fatigue strength. However, compression overloads have a more pronounced effect on the fatigue strength decrease than the tensile one (Figures 4 and 5).

The occurrence of overload seems to be a significant parameter for overloads in compression (Figures 4 and 7). Indeed, there is a significant effect of such overloads for $1 / 1000$ cycles overloads (Figure 4) but the effect is small for 1/10 000 cycles (Figure 7).

Fatigue tests carried out under constant amplitude loading with load ratio $\left(R_{\sigma}=0\right)$, did not show any influence of overloads on the fatigue strength, whatever the overload occurence or the overload sign (Figure 8) was.

Experimental results show that the overload effect strongly depends on the main loading type: $R_{\sigma}=-1$ loadings are

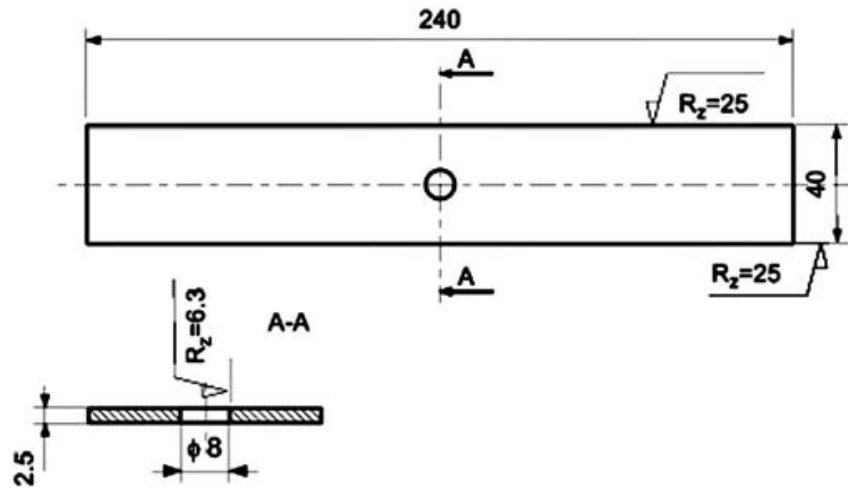

Figure 2. Specimen geometry $\left(K_{t}=2.5\right)$ more sensitive to overloads than $R_{\sigma}=0$ one. However, to further understand those results which are presented here in nominal stress, local stress-strain analysis is performed.

\section{Stress-Strain Field Calculation in Notched Specimens}

Stress-strain fields at the notch root have been computed by finite element analysis (FEA) with the simulation software ZéBuloN, developed by Mines ParisTech, Centre des Matériaux P-M. Fourt, Evry, France. A cyclic plasticity model with an isotropic and two non linear kinematic hardenings has been identified from true stress/true strain hysteresis loops obtained from strain controlled tests carried out on smooth specimens. Model parameters have been identified thanks to the optimizer program integrated in the FEA-software ZéBuloN. This has been done by considering all the true stress-strain hysteresis loops as references and not the hysteresis loops at half life as usually done. The cyclic softening occurring during the first cycles has been modeled through the non linear isotropic hardening part of the model. Figure 9 illustrates a typical comparison between a simulated and an experimental stress-strain hysteresis loop on smooth specimens. This shows the good identification of the cyclic constitutive model.

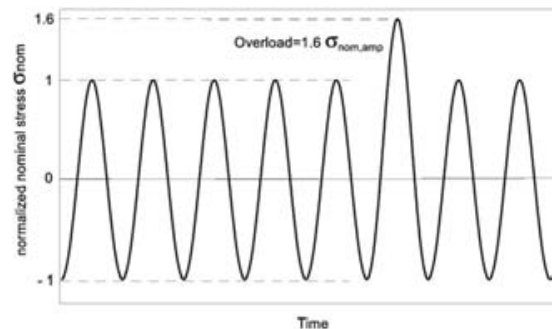

Time

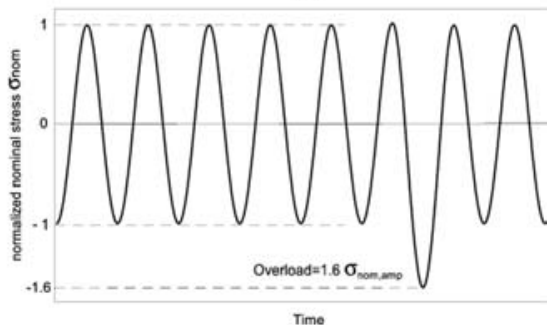

Figure 3. Constant amplitude loading with periodical overload (top) in tension (bottom) in compression

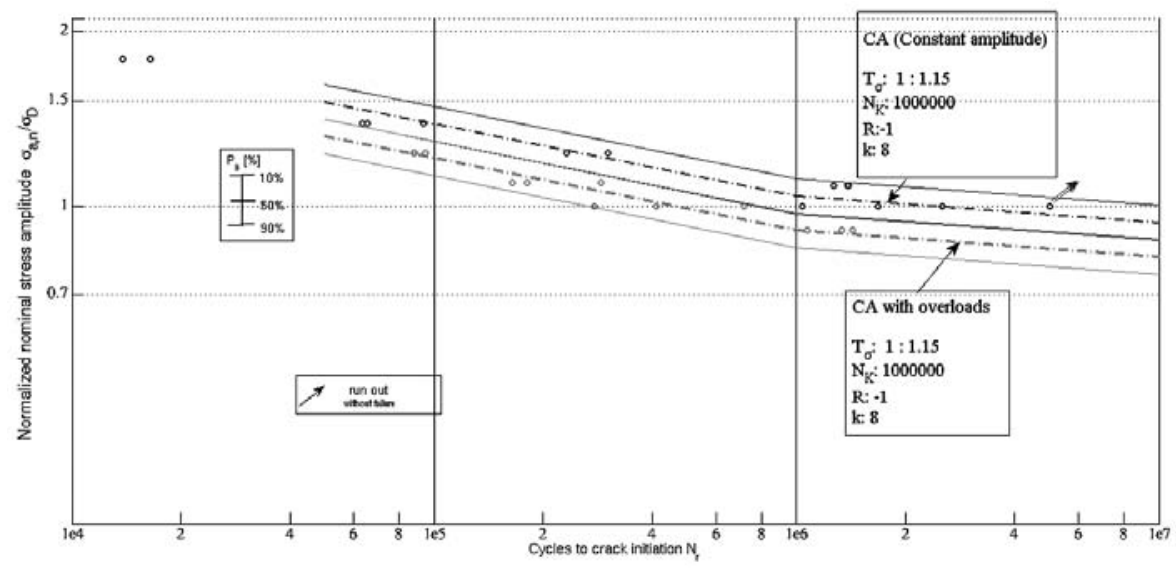

Figure 4. Constant amplitude S-N curves on notched specimens $(K t=2.5)$ under tension $\left(R_{\mathrm{\sigma}}=-1\right)$ without and with periodical compression overloads (occurrence 1/1000) 


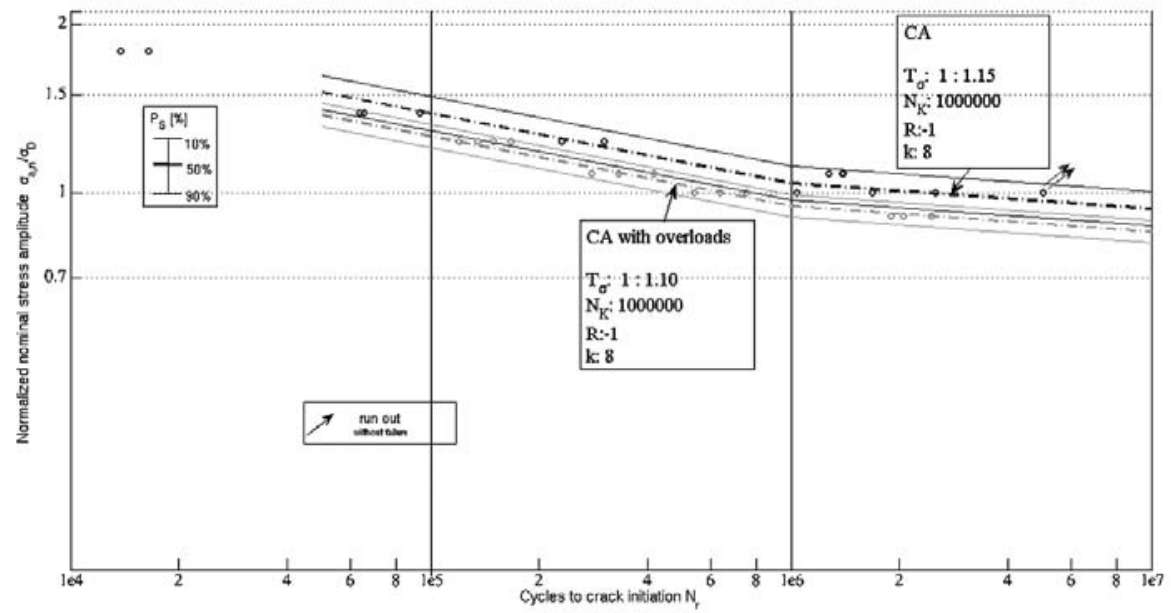

Figure 5. Constant amplitude S-N curves on notched specimens $(K t=2.5)$ under tension $\left(R_{\mathrm{\sigma}}=-1\right)$ without and with periodical tension overloads (occurrence 1/1000)

\begin{tabular}{|c|c|c|c|c|c|c|}
\hline $\begin{array}{c}\sigma_{\text {nom,amp }} / \\
\sigma_{\mathrm{D}}\end{array}$ & $\begin{array}{c}\sigma_{\text {nom,overload }} / \\
\sigma_{\mathrm{D}}\end{array}$ & $\mathrm{R}_{\sigma}$ & $\begin{array}{c}\text { Median } \\
\text { fatigue life } \\
\text { (cycles) }\end{array}$ & $\begin{array}{c}\sigma_{\text {local,max }} / \\
\sigma_{\mathrm{D}}\end{array}$ & $\begin{array}{c}\sigma_{\text {local,amp }} / \\
\sigma_{\mathrm{D}}\end{array}$ & $\begin{array}{c}\text { Stabilized } \\
\text { cyclic shake- } \\
\text { down at the } \\
\text { notch root }\end{array}$ \\
\hline 1 & no overload & -1 & $5 \cdot 10^{6}$ & 2.23 & 2.23 & Plastic \\
\hline 1 & 1.6 & -1 & $6.2 \cdot 10^{5}$ & 2.04 & 2.23 & Plastic \\
\hline 1 & -1.6 & -1 & $5 \cdot 10^{5}$ & 2.54 & 2.23 & Plastic \\
\hline 1.23 & no overload & -1 & $2.2 \cdot 10^{5}$ & 2.61 & 2.61 & Plastic \\
\hline 1.23 & 1.97 & -1 & $1.4 \cdot 10^{5}$ & 2.46 & 2.61 & Plastic \\
\hline 1.23 & -1.97 & -1 & $9 \cdot 10^{4}$ & 2.75 & 2.61 & Plastic \\
\hline 1 & no overload & 0 & $5 \cdot 10^{6}$ & 2.81 & 1.93 & Elastic \\
\hline 1 & 1.6 & 0 & $5 \cdot 10^{6}$ & 2.88 & 1.93 & Elastic \\
\hline 1 & -1.6 & 0 & $5 \cdot 10^{6}$ & 2.74 & 1.93 & Elastic \\
\hline
\end{tabular}

Table 1. Normalized axial nominal and local elastic-plastic stress at the notch root for different load cases and corresponding experimental median life (normalized cyclic yield stress: 1.4, normalized static yield stress: 2.1)

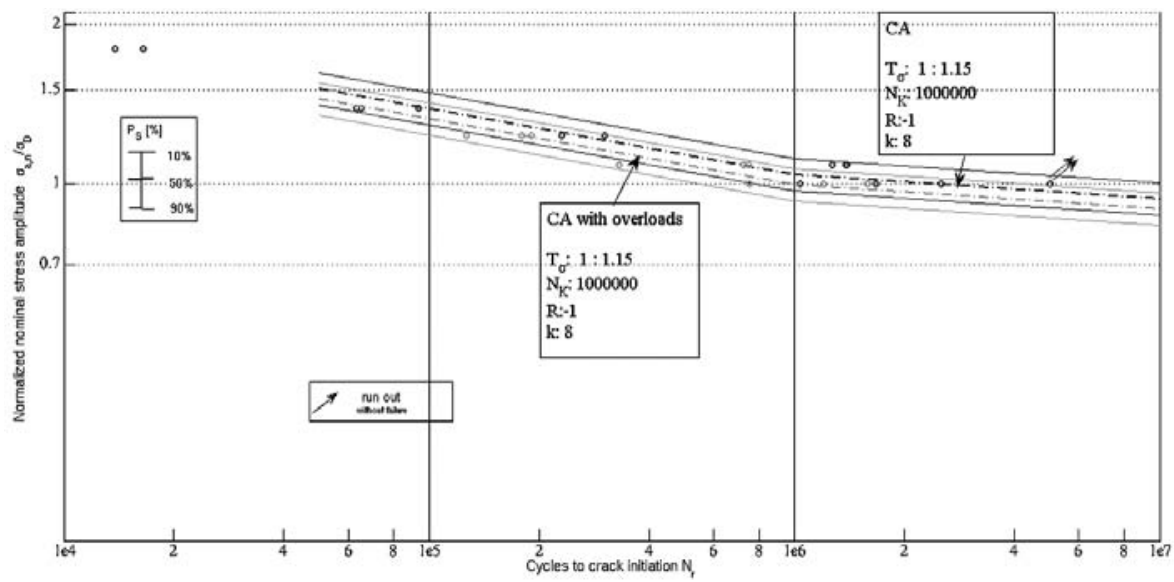

Figure 6. Constant amplitude S-N curves on notched specimen $(K t=2.5)$ under tension $R_{\mathrm{o}}=-1$ without and with periodical compression overloads and periodical tension overloads (occurrence 1/10 000)
The computed loadings consist of load controlled on notched specimens (Figure 2) under constant amplitude loading (10 cycles) and 1 periodical overload applied every 10 cycles. Only $10 \mathrm{cy}-$ cles between each overloads (instead of 10000 cycles in real loadings) were considered in the simulations since $10 \mathrm{cy}$ cles were enough to stabilize the postoverload notch root cyclic behaviour. The mesh convergence of the nocthed specimen has been checked with elasticplastic FEA. The mesh size near the notch (hole diameter $8 \mathrm{~mm}$ ) is around $50 \mu \mathrm{m}$. Since the stress state is uniaxial at the notch root only the axial elasticplastic local stress $\sigma_{\text {local }}$ is reported in Table 1.

$\sigma_{\text {local }}$ corresponds to the first principal elastic-plastic stress under constant amplitude loading after the overload application, once the cyclic behaviour is stabilized.

\section{Discussion}

Cyclic elastic-plastic FEA shows a relation between the cyclic behaviour at the notch root and the overload effect on the fatigue life. When the stabilized cyclic behaviour is an elastic shakedown, the overload does not affect the fatigue life. In parallel of this study, fatigue tests were carried out on notched specimens, with the same geometry, made of cast aluminium alloy. Due to the cyclic strain hardening of this alloy, elastic shakedown is quickly obtained at the notch root what ever the loading case. For this material overloads are found to have no effect on the fatigue life. However, even if these observations show an evident influence of the material cyclic behaviour on the overload effect, it is necessary to fall down to a lower scale than the Representative Element Volume (REV) to propose a relevant explanation of this phenomenon.

According to the authors and to literature, fatigue strength to total rupture of blunt notched specimen is depending on three phenomena:

- From observations, crack nucleation occurs at the notch root, where the local stress is the highest due to the stress concentration.

- Under constant amplitude loading, short crack nucleation does not necessarily lead to macroscopic crack. The development of mechanically small non-propagating cracks is allowed by 
the existence of a sufficiently high stress gradient due to the notch and the development of a crack closure effect [8-10].

- Moreover, even if the notch is not sharp enough to generate a significant crack closure effect, the local cyclic stress must be high enough to initiate a crack at the notch and overcome the microstructural barriers to cause crack propagation until macroscopic crack ( $1 \mathrm{~mm}$ long) or total rupture [8-11].

Observations performed on our material have not yet shown clearly such phenomena. The work in progress aims to experimentally verify two major points:

1. measure the cyclic stress/strain response at the notch root for the two different materials to compare the computed stress state to the experimentally observed one.

2. interrupted SEM test to further understand the role of non-propagating micro-cracks in the overload effect.

\section{Conclusions}

Experimental results showed a detrimental influence of the overloads on the fatigue crack initiation life under fully revered axial loading. To explain this overload effect, one can assume the addition of two effects: on one hand a modification of the crack closure due to the overload residual stresses generated by overload, and on the other hand the rapid small crack overcoming of microstructural barriers due to overloads. Next SEM observations will allow to validate, or not, this hypothesis and probably give additional information to explain the non-effect of overload on fatigue crack initiation life for the load ratio $R_{\sigma}=0$.

\section{References}

1 F. Ellyin: Fatigue Damage, Crack Growth and Life Prediction, Chapman \& Hall Ed. (1997), p. 470

2 E. Charkaluk, A. Bignonnet, A. Constantinescu, K. Dang Van: Fatigue design of structures under thermomechanical loadings, Fat. Fract. Engng. Mat. Struct., 25 (2002), No. 12, pp. 1199-1206

3 C. M. Sonsino, H. Kaufmann,V. Grubisic: Transferability of material data for the example of a randomly loaded forged truck stub axle, Journal of Mat. and Manuf. 106 (1997), No. 5, pp. 649-670

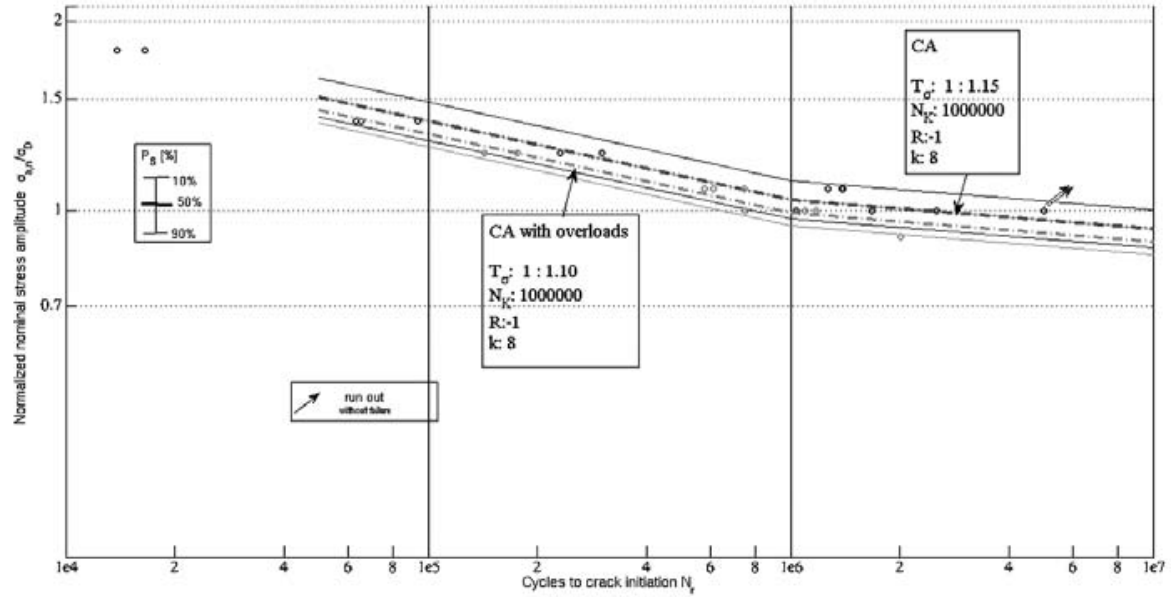

Figure 7. Constant amplitude $S$ - $N$ curves on notched specimen $(K t=2.5)$ under tension $\left(R_{\mathrm{o}}=-1\right)$ without and with periodical compression overloads (occurrence 1/10 000)

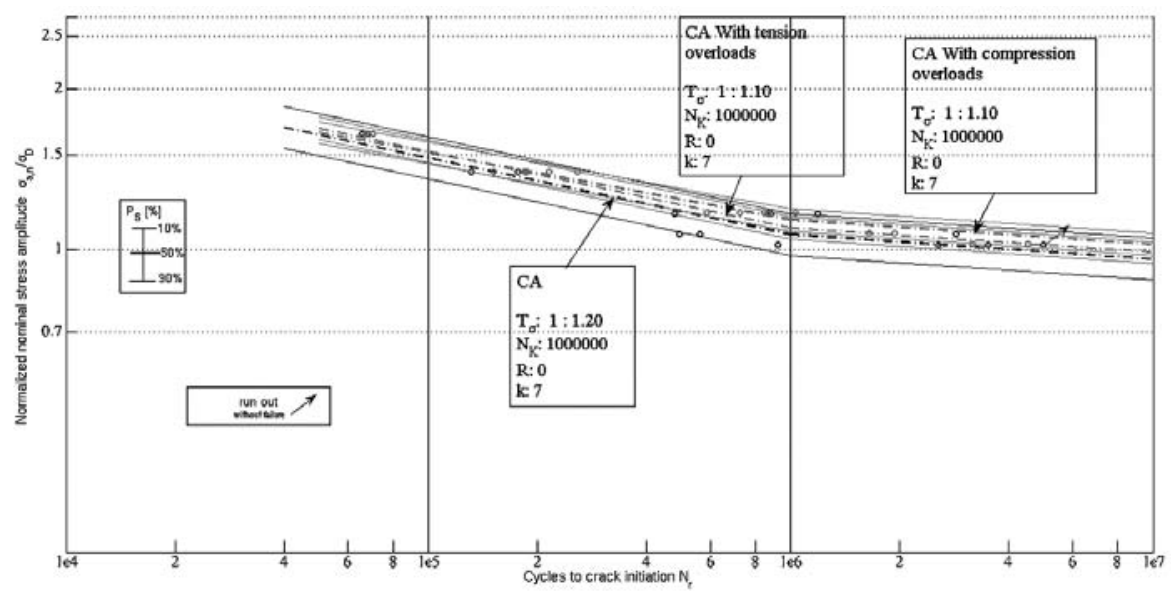

Figure 8. Constant amplitude $S$ - $N$ curves on notched specimen $(K t=2.5)$ under tension $\left(R_{\sigma}=0\right)$ without and with periodical compression overloads and periodical tension overloads (occurrence 1/1000)

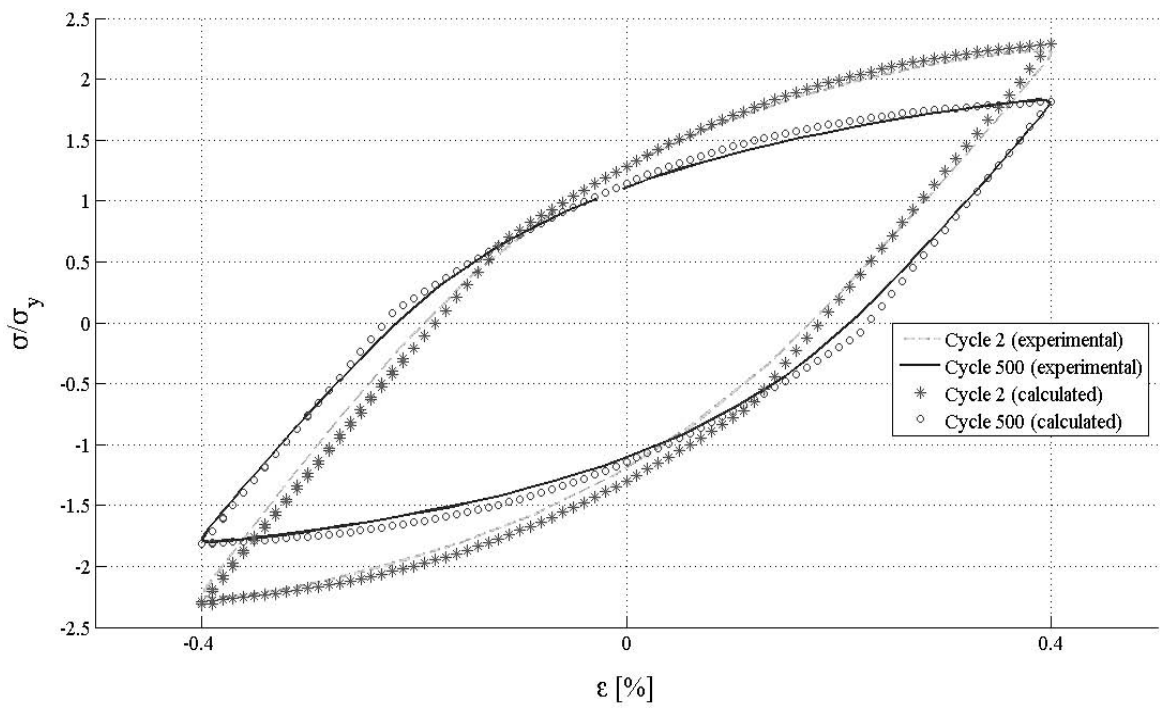

Figure 9. Simulated and experimental cyclic stress strain hysteresis loop on smooth specimen 
4 D. T. Jelaska: Fatigue assessment for combined HCF/LCF loading, ASME Publication PVP 451 (2002), No. 6, pp. 135-140

5 S. Mall, T. Nicholas, T-W. Park: Effect of predamage from low cycle fatigue on high cycle fatigue strength of Ti-6Al-4V, Int. J. Fatigue 25 (2003), pp. 1109-1116

6 H. Kaufmann, C. M. Sonsino: High-strength welded steels under overloads, Int. HighStrength Steel Conference, Rome (2005)

7 X. L. Zheng: Overload effects on the fatigue behaviour and life prediction of low carbon steels, Int. J.Fatigue 17 (1994), No. 5, pp. 331-337

8 M. D. Chapetti: Prediction of the fatigue limit of blunt-notched components, Int. J. Fatigue 23 (2001), pp. 171-176

9 M. D. Chapetti, N. Katsura, T. Tagawa, T. Miyata: Static strengthening and fatigue blunt-notch sensitivity in low carbon steels, Int. J.Fatigue 23 (2001), pp. 207-214

10 M. D. Chapetti: Fatigue propagation threshold of short cracks under constant amplitude loading, Int. J. Fatigue 25 (2003), pp. 1319-1326

11 V. Doquet and S. Taheri: Effet d'un préecrouissage ou d'un sur écrouissage cyclique sur la durée de vie en fatigue de divers aciers à contrainte ou déformation imposée, Revue Française de Mécanique (2000), pp. 84-92

\section{The Authors of this Contribution}

Hadrien Bidouard obtained a Master of Research in the field of mechanics and material at the University of Paris XI in 2005, he is preparing a $\mathrm{PhD}$ thesis about "Overload effect on fatigue life of ferritic-bainitic steel under variable amplitude loading". He worked as a Research Engineer during his PhD preparation at the Renault Technocentre (Guyancourt, France).

Prof. Dr.-Ing. Thierry Palin-Luc obtained an engineering diploma at ENSAM in 1991, he prepared a PhD thesis about "The multiaxial fatigue of spheroidal graphite cast iron under combined loadings" (defended in 1996). From 1997 to 2008, he was assistant professor at LAMEFIP ENSAM. He is full professor at Arts et Métiers ParisTech since September 2008. From 2004, he is the head of the „Fatigue of Materials and Structures" activity of LAMEFIP. From 2005 Prof. Palin-Luc is Deputy Director of this laboratory, his research activities are on the multiaxial fatigue of materials and structures. He has developed volumetric energy based multiaxial fatigue models, and he studies interaction between the fatigue life of structures and manufacturing processes.

Dr. Ing. Nicolas Saintier is assistant professor at the Department of Mechanical Engineering of Arts et Métiers ParisTech since 2004. He obtained his doctoral degree from the Ecoles Des Mines in 2001 in the field of multiaxial fatigue. His research activities concern the development of fatigue criteria under complex loading (variable amplitude non proportional loadings) for metallic and non-metallic materials (polymers, rubber). His latest research interests are focussed on further understanding the link beween microstructure and fatigue damage processes in order to propose tools for process optimization towards fatigue resistance.

Dipl.-Ing. Christian Dumas has obtained his diploma in 1990. He works at Renault SAS since 1996. After being in charge of cold forming process simulation and fatigue design at the Engine Department, he became responsible for fatigue testing team at Materials Engineering Department of Renault Guyancourt in 2002.

The activity concerns the characterization of materials for Engine and Vehicle design, the development of fatigue criteria under multi axial fatigue on metallic and polymers parts.

Dr. Heinz Kaufmann studied Mechanical Engineering at the Technical University Darmstadt (TUD). In 1986 he joined the Fraunhofer Institute for Structural Durability and System Reliability LBF in Darmstadt, Germany, where he worked on the fatigue behaviour of cast materials (aluminium, magnesium, thin- and thick-walled ductile cast iron), forged steels and welded joints (steel/aluminium). He presented his doctoral thesis on 'The Dimensioning of Cyclically-Loaded Thick-Walled Components of Cast Ductile Iron GGG-40 Considering Microstructural Degenerations from Casting' at Saarbruecken University in 1998. Since 2003 he is head of the Competence Center „Component-Related Material Behaviour“.
The tasks of the Competence Center are the experimental and numeric analysis of the fatigue properties of materials und structures considering the manufacturing technologies, loading and environmental conditions.

Dipl.-Ing. Chalid el Dsoki studied Mechanical Engineering at the Technical University Hannover and the Technical University of Berlin. Subject of his diploma thesis was „Simulation of an Otto-Engine“. Since mid of 2005 he is with the Fraunhofer Institute for Structural Durability and System Reliability LBF as well as with the Technical University of Darmstadt in the Department System Reliability and Machine Acoustics SzM. Actually he is working on the topics cold forming, neural networks, and material laws for describing the elastic-plastic fatigue behaviour.

Prof. Dr.-Ing. Cetin Morris Sonsino studied Mechanical Engineering at the Technical University Darmstadt (TUD) and works at the Fraunhofer-Institut für Betriebsfestigkeit und Systemzuverlässigkeit LBF in Darmstadt since 1973. He achieved his doctoral degree in the field of cold forming and low-cycle fatigue in 1982. Since 1990 he is lecturing at the Saarland University, and since 2002 also at the Technical University Darmstadt the course Structural Durability - Component Related Material Behaviour. Prof. Sonsino is chairman of the DVM working group Structural Durability and is deputy director of the LBF.

\section{Abstract}

Auswirkungen von LCf-Belastungen auf die HCf-Lebensspanne von Prüfkörpern in ferritisch-bainitischem Stahl. Ermüdungsversuche wurde für Prüfkörper aus ferritisch-bainitischem Stahl $(\mathrm{Kt}=2,5)$ unter Belastungen mit kontrollierter konstanter Amplitude durchgeführt. Diese Versuche zeigen, dass bei Zug-Druck-Belastung mit konstanter Amplitude periodisch ausgeübte Überbelastungen einen negativen Effekt auf die Anfangsstärke von Ermüdungsrissen für das vollständig umgekehrte Belastungsverhältnis $\left(R_{\sigma}=-1\right)$, während sie unter einer pulsierenden Belastung $\left(R_{\sigma}=0\right)$ keine Wirkung zeigen. Eine Finite Element-Analyse zeigt, dass für die vollständig umgekehrte Zugspannung $\left(\mathrm{R}_{\sigma}=-1\right)$, das stabilisierte zyklische Verhalten beim Prüfkörper ein elastisch-plastischer Shakedown ist, während ein elastischer Shakedown unter pulsierender Bedingung $\left(\mathrm{R}_{\sigma}=0\right)$ erhalten wird. So können wir folgern, dass das lokale zyklische Verhalten einen Einfluss auf den Überbelastungseffekt hat. Die Überbelastung impliziert aber keine nennenswerte Modifikation des Spannungs-Dehnungs-Felds unter der nachfolgenden Belastung mit konstanter Amplitude und kann eine solche Abnahme der Ermüdungsfestigkeit bei vollständig umgekehrter Spannung nicht erklären.

You will find the article and additional material by entering the document number MP110069 on our website at www.materialstesting.de 